\title{
Correction to: Mu Opioids Induce Biased Signaling at the Full-Length Seven Transmembrane C-Terminal Splice Variants of the mu Opioid Receptor Gene, Oprm 1
}

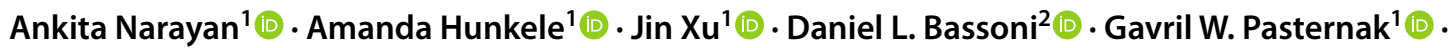 \\ Ying-Xian $\operatorname{Pan}^{1,3}$
}

Published online: 31 October 2020

(c) Springer Science+Business Media, LLC, part of Springer Nature 2020

\section{Correction to: Cellular and Molecular Neurobiology https://doi.org/10.1007/s10571-020-00973-5}

The original version of this article unfortunately contained a typo in co-author name.

The author name is "Amanda Hunkele" instead it was published incorrectly as "Amanda Hunkle".

The original article has been corrected.
The original article can be found online at https://doi.org/10.1007/ s10571-020-00973-5.

Ying-Xian Pan

pany@mskcc.org; yx.pan@ rutgers.edu

1 Department of Neurology and the Molecular Pharmacology Program, Memorial Sloan Kettering Cancer Center, 1275

York Ave, New York, NY 10065, USA

2 Eurofins DiscoverX, Fremont, CA, USA

3 Department of Anesthesiology, Rutgers New Jersey Medical School, 185 South Orange Avenue, Newark, NJ 07103, USA
Publisher's Note Springer Nature remains neutral with regard to jurisdictional claims in published maps and institutional affiliations. 